\title{
Composto orgânico no potencial fisiológico de sementes de brócolis após o armazenamento
}

\section{Organic compost in physiological potential of broccoli seeds after storage}

\author{
Felipe Oliveira Magro ${ }^{1 *}$; Antonio Ismael Inácio Cardoso ${ }^{2}$; \\ Dirceu Maximino Fernandes ${ }^{3}$
}

\begin{abstract}
Resumo
O trabalho foi conduzido com o objetivo de avaliar a germinação e o vigor de sementes de brócolis (cultivar Ramoso Santana) obtidas de plantas cultivadas com diferentes doses de composto orgânico e armazenadas em câmara seca. $\mathrm{O}$ delineamento experimental utilizado na produção de sementes foi $\mathrm{o}$ de blocos casualizados, com cinco tratamentos $\left(0 ; 30 ; 60 ; 90\right.$ e 120 t ha $^{-1}$ de composto orgânico marca comercial Biomix $^{\circledR}$ ) e quatro repetições. Logo após a colheita e durante a armazenagem aos 12 e 24 meses em câmara seca $\left(20^{\circ} \mathrm{C}\right.$ e $40 \%$ UR) foi avaliada a germinação e o vigor (primeira contagem da germinação e índice de velocidade de germinação - IVG). Não houve diferenças na germinação e vigor nas sementes recém colhidas e aos 12 meses de armazenamento. Aos 24 meses de armazenamento das sementes, quanto menores as doses de composto orgânico, menores foram o percentual de germinação e o IVG, com valores respectivos, na ausência de composto, de $69 \%$ e 12,3. Já os maiores valores de germinação e IVG, $82 \%$ e 16,1 , respectivamente, foram obtidos na maior dose de composto orgânico $\left(120 \mathrm{tha}^{-1}\right)$.
\end{abstract}

Palavras-chave: Brassica oleracea var. italica, adubação orgânica, germinação

\begin{abstract}
The study was carried out with the objective to evaluate the broccoli seeds (cultivar Ramoso Santana) germination and vigor from plants cultivated with different organic compost levels and after storage in dry chamber. At seed production stage, the experiment was conducted in randomized complete blocks design, with five treatments $\left(0 ; 30 ; 60 ; 90\right.$ and 120 tha $^{-1}$ of Biomix ${ }^{\circledR}$ organic compost $)$ and four replications. Soon after harvesting and after 12 and 24 months of conservation in dry chamber room $\left(20^{\circ} \mathrm{C}\right.$ and $40 \%$ relative humidity) it was evaluated germination, following seed analisys rules, and vigor (first count of germination and germination speed index - IVG). There were no differences in germination and vigor in seeds as soon as they were harvested and after 12 month of storage. After 24 months of storage, the lesser the organic compost rates, the lesser seed germination and IVG, with respective values, without compost, of $69 \%$ and 12,3 . For another hand, the highest values for germination and $\mathrm{IVG}, 82 \%$ and 16,1 , respectively, were obtained with the highest rate of organic compost $\left(120 \mathrm{tha}^{-1}\right)$.
\end{abstract}

Key words: Brassica oleracea var. italica, organic fertilization, germination

\footnotetext{
${ }^{1}$ Eng $^{\mathrm{o}}$ Agr $^{\mathrm{o}}$, Doutorando, Dept ${ }^{\circ}$ de Produção Vegetal, Setor Horticultura, Faculdade de Ciências Agronômicas, Universidade Estadual Paulista/UNESP. Botucatu, SP. E-mail: felipe_magro@yahoo.com.br

${ }^{2}$ Eng $^{\mathrm{o}}$. Agr ${ }^{\mathrm{o}}$, Prof. Dr. Adjunto do Dept ${ }^{\mathrm{o}}$ de Produção Vegetal, Setor Horticultura da UNESP, Botucatu, SP. Bolsista de Produtividade do CNPq. E-mail: ismaeldh@fca.unesp.br

${ }^{3}$ Eng $^{\mathrm{o}} \mathrm{Agr}^{\mathrm{o}}$, Prof. Dr. Adjunto do Dept ${ }^{\mathrm{o}}$ de Recurso Naturais/Ciência do Solo da UNESP, Botucatu, SP. Bolsista de Produtividade do CNPq. E-mail: dmfernandes@fca.unesp.br

* Autor para correspondência
} 
Existem poucos trabalhos que relacionam a adubação e a nutrição das plantas com a produção e a qualidade fisiológica das sementes, e os resultados nem sempre são concordantes (CARVALHO; NAKAGAWA, 2000). Trabalhos que abordem os efeitos dos nutrientes na qualidade fisiológica das sementes após o armazenamento são mais escassos ainda.

A qualidade das sementes não pode ser melhorada durante o armazenamento, mas pode ser preservada quando as condições de conservação são favoráveis. Segundo Pádua e Vieira (2001), lotes de sementes com percentagens de germinação semelhantes, mas com diferentes níveis de vigor, podem apresentar comportamentos diferenciados em relação à deterioração, sendo esta maior em condições de temperatura e umidade relativa elevadas, além do tempo de armazenamento. Geralmente, quanto maior o vigor inicial do lote de sementes, maior o período que as mesmas mantém-se capazes de germinar e resultar em plântulas vigorosas.

A qualidade das sementes é dependente de uma série de fatores, em particular do estado nutricional das plantas que as produziram. De modo geral, a adubação pode aumentar a produção de sementes, sendo, geralmente, explicado devido ao melhor desenvolvimento das plantas (características vegetativas). No entanto, as relações com o potencial fisiológico das sementes, não têm sido evidenciadas consistentemente pela pesquisa. Talvez a maior dificuldade para a elucidação desse fato, esteja na metodologia adotada pelos pesquisadores e não devido à inexistência de relação entre o estado nutricional da planta ou a fertilidade do solo e o potencial fisiológico das sementes (MARCOS FILHO, 2005).

Outro fator, a ser considerado, é que as plantas desenvolveram uma extraordinária capacidade de ajustar a produção de sementes aos recursos disponíveis. A resposta típica de plantas à baixa fertilidade do solo é a diminuição na quantidade de sementes produzidas, e somente depois há redução na qualidade. As poucas sementes produzidas sob condições de baixa fertilidade são usualmente tão viáveis e vigorosas como as produzidas sob situações mais favoráveis. Do ponto de vista evolucionário, os ajustes da produção de sementes aos recursos disponíveis têm um alto valor para a sobrevivência. As poucas sementes de alta qualidade teriam chance de germinar e desenvolver-se em condições adversas (DELOUCHE, 1980). Há também relatos que o efeito da nutrição das plantas na qualidade da semente possa ser observado só após algum período de armazenamento das sementes (ZUCARELI, 2005).

É reconhecido o efeito benéfico da adubação orgânica na produtividade das culturas. Os nutrientes presentes no composto orgânico, principalmente o nitrogênio e o fósforo, possuem liberação mais lenta quando comparadas com adubos minerais, o que muitas vezes favorece o aproveitamento (RAIJ et al., 1996). Já o potássio, apesar de ser encontrado em apenas uma pequena porção contida na matéria orgânica, está presente na forma livre, sendo prontamente liberado para o solo (KIEHL, 1985). Considerando que tanto o nitrogênio, quanto o fósforo e o potássio são translocados em quantidades consideráveis durante a formação das sementes, a adubação com composto orgânico pode constituir uma prática que pode contribuir para a produção de sementes de elevado potencial fisiológico.

$\mathrm{Na}$ literatura consultada, não foram encontrados trabalhos relacionando adubação orgânica com qualidade fisiológica de sementes após o armazenamento. Os poucos trabalhos que relacionam adubação, potencial fisiológico e armazenamento, tem tido principalmente a adubação com fósforo como objeto de estudo. Os efeitos benéficos da adubação fosfatada no vigor de sementes após períodos de armazenamento foram verificados na cultura do amendoim (NAKAGAWA; ROSOLEM; MACHADO, 1980), em sementes de aveia-preta (NAKAGAWA; CAVARIANI; GUISCEM, 2001) e alface (KANO et al., 2011). 
Embora existam estudos sobre nutrição e recomendações de adubação para o cultivo comercial de brócolis, raramente encontram-se trabalhos que abordem os efeitos dos nutrientes na produção de sementes e, principalmente, na qualidade fisiológica das mesmas. O objetivo deste trabalho foi avaliar a qualidade fisiológica de sementes de brócolis, obtidas de plantas cultivadas com diferentes doses de composto orgânico, logo após a colheita e após armazenamento por 12 e 24 meses.

O trabalho foi desenvolvido na Fazenda Experimental São Manuel, localizada no município de São Manuel/SP, pertencente à Faculdade de Ciências Agronômicas (FCA) da Universidade Estadual Paulista (UNESP), Campus de Botucatu/ SP, localizada à latitude sul de $22^{\circ} 46^{\prime}$, longitude oeste de $48^{\circ} 34^{\prime}$ 'e altitude de $740 \mathrm{~m}$.

As plantas foram cultivadas em estruturas de cultivo protegido, tipo arco, com $20 \mathrm{~m}$ de comprimento, largura de $7 \mathrm{~m}$ e pé direito de 1,8m. Foi utilizada a cultivar Ramoso Santana. A semeadura foi realizada no dia 25/06/2007. As mudas foram transplantadas em 25/07/2007 para vasos de plástico com capacidade de 13 litros (diâmetro superior, inferior e altura de 30, 22 e 27 $\mathrm{cm}$, respectivamente), sendo cultivada uma planta por vaso, com espaçamento entre linhas de $1,0 \mathrm{~m}$ e $0,5 \mathrm{~m}$ entre plantas (centro a centro dos vasos, com os vasos ficando a uma distância de $20 \mathrm{~cm}$ entre eles). Cada parcela foi constituída de seis plantas, das quais as três mais homogêneas foram consideradas úteis.

O solo utilizado no experimento foi classificado por Espíndola, Tosin e Paccola (1974), como Latossolo Vermelho Escuro fase arenosa, denominado pela nomenclatura do Sistema Brasileiro de Classificação de Solos (EMBRAPA, 2006), como Latossolo Vermelho Distrófico Típico. A análise química do solo indicou: $\mathrm{pH}$ em $\mathrm{CaCl}_{2}=$ 4,2; M.O. $=4 \mathrm{~g} \mathrm{dm}^{-3} ; \mathrm{H}^{+}+\mathrm{Al}^{3+}=24 \mathrm{mmol}_{\mathrm{c}} \mathrm{dm}^{-3} ; \mathrm{K}^{+}=$ $0,3 \mathrm{mmol}_{\mathrm{c}} \mathrm{dm}^{-3} ; \mathrm{P}$ resina $=1 \mathrm{~g} \mathrm{dm}^{-3} ; \mathrm{Ca}^{2+}=2 \mathrm{mmol}_{\mathrm{c}}$ $\mathrm{dm}^{-3} ; \mathrm{Mg}^{2+}=1 \mathrm{mmol}_{\mathrm{c}} \mathrm{dm}^{-3} ; \mathrm{SB}=3 \mathrm{mmol}_{\mathrm{c}} \mathrm{dm}^{-3} ;$ $\mathrm{CTC}=28 \mathrm{mmol}_{\mathrm{c}} \mathrm{dm}^{-3} \mathrm{e} \mathrm{V} \%=12$.

Utilizou-se o delineamento experimental de blocos casualizados com quatro repetições. Os tratamentos foram constituídos de quatro doses de composto orgânico da marca comercial Biomix ${ }^{\circledR}$, equivalentes à $30,60,90$ e $120 \mathrm{t} \mathrm{ha}^{-1}$, além da testemunha sem composto.

A análise química do composto indicou valor de $\mathrm{pH}$ de 7,96 e os valores de $\mathrm{MO} ; \mathrm{N} ; \mathrm{P}_{2} \mathrm{O}_{5} ; \mathrm{K}_{2} \mathrm{O} ; \mathrm{Ca}$; $\mathrm{Mg}$ e de $\mathrm{S}$ expressos em \% respectivamente de: 40 ; 0,$72 ; 0,27 ; 0,33 ; 9,15 ; 0,19$ e 0,16 . A relação $\mathrm{C} / \mathrm{N}$ foi de 31 e a umidade do composto foi de $54,5 \%$. Os valores para os micronutrientes $\mathrm{Cu}, \mathrm{Fe}, \mathrm{Mn}$ e $\mathrm{Zn}$, foram expressos em mg kg-1 e iguais a $150 ; 7400$; 158 e 270; respectivamente. Foi feita a correção do solo de modo a elevar a saturação por bases a $80 \%$ e a adubação de plantio consistiu no fornecimento de 22 gramas de superfosfato simples por vaso (RAIJ et al., 1996), além do composto orgânico conforme os tratamentos. Como adubação foliar, a cultura recebeu uma única aplicação de ácido bórico, na dosagem de $1 \mathrm{~g} \mathrm{~L}^{-1}$ aos 15 dias após o transplante.

As plantas foram tutoradas de modo a evitar o tombamento das mesmas na fase reprodutiva e a irrigação foi realizada por meio de gotejadores instalados individualmente nos vasos. A colheita de sementes foi realizada parceladamente, quando mais de $50 \%$ das siliquas de cada planta encontravam-se secas, iniciando-se no dia 26/11/2007 com término no dia 07/01/2008. As sementes foram levadas para câmara seca a $40 \%$ de umidade relativa e a temperatura de $20^{\circ} \mathrm{C}$ para conservação.

Após o término das colheitas, realizou-se o teste de germinação com utilização de caixas de plástico (gerbox) em germinador a $20^{\circ} \mathrm{C}$. Novos testes foram realizados aos 12 e 24 meses após a colheita, também a $20^{\circ} \mathrm{C}$, conforme as Regras de Análise de Sementes (BRASIL, 2009). Nestes períodos, as sementes ficaram armazenadas em embalagens permeáveis (sacos de papel) e mantidas em câmara seca $\left(20^{\circ} \mathrm{C}\right.$ e umidade relativa de $\left.40 \%\right)$. 
As avaliações de qualidade das sementes foram realizadas no Setor de Horticultura da Faculdade de Ciências Agronômicas (FCA/UNESP) em BotucatuSP. A cada período de armazenamento foram avaliadas as seguintes características: germinação, primeira contagem de germinação e índice de velocidade de germinação (IVG). A primeira contagem das plântulas normais foi realizada aos cinco dias e a segunda no décimo dia. As plântulas foram consideradas germinadas ao perceber $\mathrm{o}$ aparecimento das folhas cotiledonares. A primeira contagem de germinação foi considerada como teste de vigor, em que as amostras que germinam mais rapidamente, com maior porcentagem de germinação nessa data, são consideradas como mais vigorosas (VIEIRA; CARVALHO, 1994). A obtenção do IVG foi realizada durante o teste de germinação, conforme Maguire (1962). As avaliações foram diárias e realizadas sempre no mesmo horário até o décimo dia após a semeadura. Quanto maior o valor do IVG, maior o vigor das sementes.

Para verificar o efeito das doses de composto orgânico nos testes de germinação nas três épocas avaliadas (logo após a colheita, aos 12 e aos 24 meses após o armazenamento), realizou-se análise de variância e teste $\mathrm{F}$ em cada período, sendo os dados, quando necessário, submetidos à análise de regressão.

Não houve diferença entre as doses de composto orgânico logo após a colheita e com 12 meses de armazenamento das sementes, porém, aos 24 meses houve aumento linear na porcentagem de germinação, primeira contagem de germinação e para o IVG em função do aumento das doses (Figura 1). Em geral, observou-se que os valores de IVG e primeira contagem aos 24 meses de armazenamento foram menores que os observados após a colheita de sementes e aos 12 meses de armazenamento em câmara seca. Esse resultado demonstra a diminuição no vigor das sementes em todos os tratamentos, sendo mais pronunciado nas menores doses de composto orgânico.
Para a germinação, apesar da redução linear quanto menor a dose de composto orgânico, as diferenças entre os períodos foram menores, mostrando que o vigor foi mais influenciado pelo armazenamento que a germinação.

Resultado semelhante foi obtido por Nakagawa, Rosolem e Machado (1980), ao avaliarem o efeito da adubação fosfatada no vigor de sementes de amendoim. Os autores verificaram que aos nove meses de armazenamento os tratamentos que receberam doses de $\mathrm{P}_{2} \mathrm{O}_{5}$ mais altas, apresentaram sementes com maior porcentagem de emergência em relação ao tratamento que não recebeu adubação fosfatada. Além disso, observaram diminuição gradual do vigor das sementes com o decorrer do armazenamento. Já Nakagawa, Cavariani e Guiscem (2001) verificaram que aos 18 meses após a colheita, sementes de aveia-preta apresentaram redução da qualidade em todos os tratamentos (doses crescentes de $\mathrm{P}_{2} \mathrm{O}_{5}$ ), comparativamente às avaliações realizadas aos quatro meses.

Rosseto, Nakagawa e Rosolem (1997) avaliaram o efeito da adubação potássica na qualidade fisiológica de sementes de canola imediatamente após a colheita e aos seis meses de armazenamento e verificaram que a adubação favoreceu a germinação e o vigor só após o armazenamento das sementes, o que também foi verificado neste experimento.

Kano et al. (2011) avaliaram cinco doses de $\mathrm{P}_{2} \mathrm{O}_{5}$ em solo com baixo teor de fósforo no cultivo da alface destinada a produção de sementes e verificaram que as doses não afetaram a qualidade fisiológica das sementes logo após a colheita e aos 15 meses de armazenamento, porém após 25 meses foi constatada redução linear da germinação e do vigor quanto menor foi a dose de fósforo. Neste experimento com brócolis, o resultado foi semelhante, com redução na germinação e vigor das sementes somente após 24 meses de armazenamento, quanto menor a quantidade de adubo; na presente pesquisa, na forma de composto orgânico, ao invés de adubo químico fosfatado. 
Figura 1. Porcentagem de sementes germinadas, primeira contagem de germinação e índice de velocidade de germinação (IVG) obtido no teste de germinação após a colheita $\left(\mathrm{y}_{0}\right)$, aos $12\left(\mathrm{y}_{12}\right)$ e aos $24\left(\mathrm{y}_{24}\right)$ meses de armazenamento das sementes de brócolis, cultivar Ramoso Santana, em função das doses de composto orgânico aplicadas no solo.
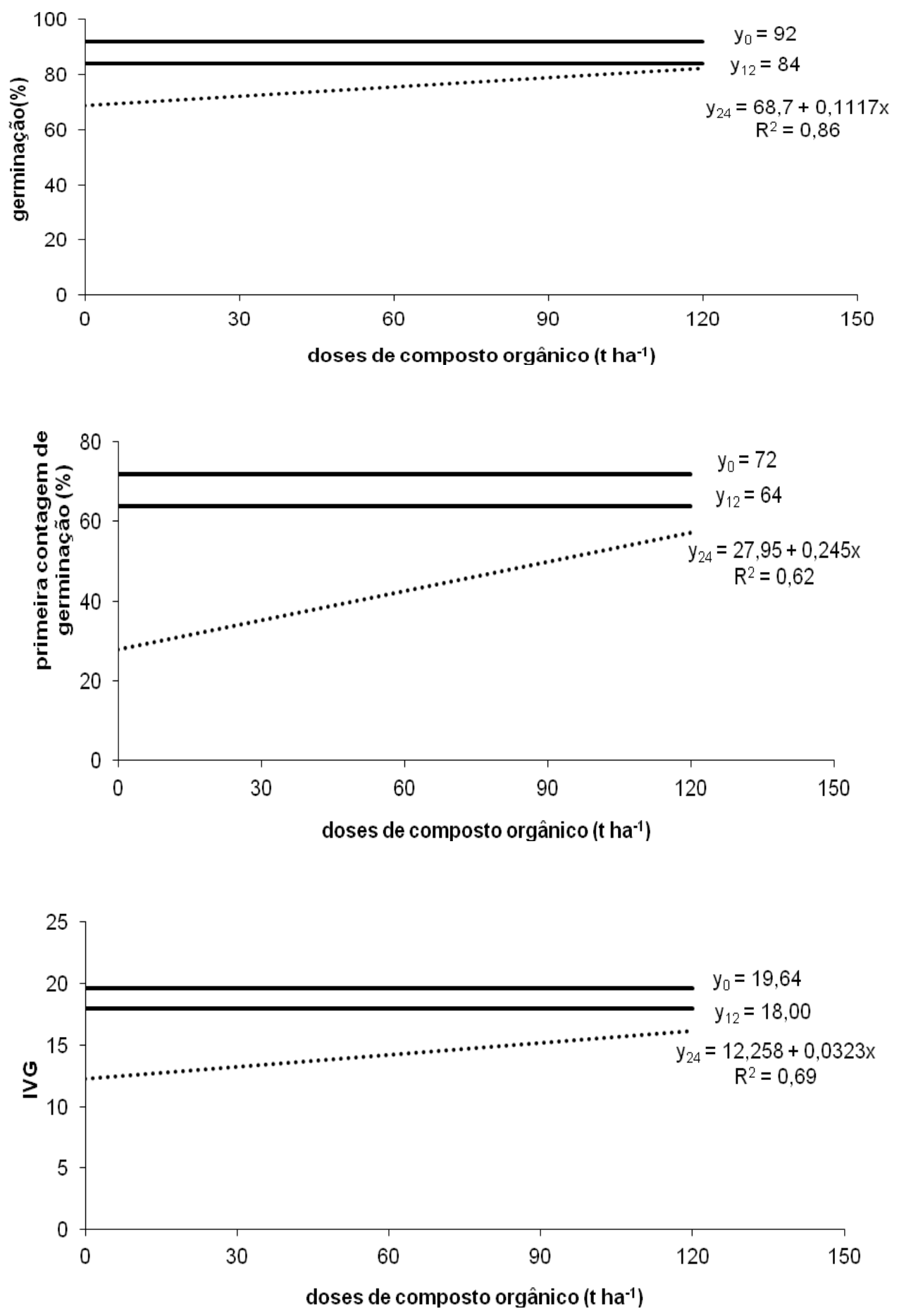

Fonte: Elaboração dos autores. 
Portanto, a diferenciação do potencial fisiológico das sementes produzidas com diferentes doses de composto orgânico só foi possível, com o teste padrão de germinação, após dois anos de armazenamento, concordando com Zucareli (2005), que relata que o efeito da nutrição das plantas na qualidade da semente possa ser observado somente após período de armazenamento. Assim como neste trabalho, Kano et al. (2011) também verificaram a influência da adubação com doses de fósforo somente após 24 meses de armazenamento em sementes de alface. No entanto, os autores citados não explicam o provável motivo da perda de qualidade das sementes, indicando que novas pesquisas devem ser realizadas visando obter explicação para o fato de sementes obtidas em plantas cultivadas em diferentes condições de fertilidade do solo, ou níveis de adubação, só apresentarem diferença de germinação e vigor após determinado tempo de armazenamento em condições ideais.

A maior dose utilizada possibilitou que as sementes de brócolis, após 24 meses de armazenamento, apresentassem germinação de $82 \%$ e IVG de 16,1, mantendo o padrão de qualidade exigido pelo MAPA, o qual determina $75 \%$ de germinação mínima para a comercialização de sementes desta cultura.

Conclui-se que as doses de composto não influenciaram a qualidade das sementes de brócolis logo após a colheita e aos 12 meses de armazenamento, sendo que quanto maior a dose (0 à 120 tha $\left.^{-1}\right)$ maior o vigor e a germinação das sementes somente após 24 meses de armazenamento.

\section{Agradecimentos}

À Capes pela concessão da bolsa de doutorado ao primeiro autor.

\section{Referências}

BRASIL. Ministério da Agricultura, Pecuária e Abastecimento. Regras para análise de sementes. Ministério da Agricultura, Pecuária e Abastecimento. Secretaria de Defesa Agropecuária. Brasília, DF: Mapa/ ACS, 2009. 395 p.

CARVALHO, N. M.; NAKAGAWA, J. Sementes: ciência, tecnologia e produção. 4. ed. Jaboticabal: FUNEP, 2000. $588 \mathrm{p}$.

DELOUCHE, J. C. Environmental effects on seed development and seed quality. HortScience, Alexandria, v. 15 , n. 6, p. 775-780, 1980.

EMPRESA BRASILEIRA DE PESQUISA AGROPECUÁRIA - EMBRAPA. Centro Nacional de Pesquisa de Solos (Rio de Janeiro, RJ). Sistema brasileiro de classificação de solos. Rio de Janeiro: Embrapa, 2006. $306 \mathrm{p}$.

ESPÍNDOLA, C. R.; TOSIN, W. A. C.; PACCOLA, A. A. Levantamento pedológico da Fazenda Experimental São Manuel. In: CONGRESSO BRASILEIRO DE CIÊNCIA DO SOLO, 14., 1974, Santa Maria. Anais... Santa Maria: Sociedade Brasileira de Ciência do Solo, 1974. p. 650-654.

KANO, C.; CARDOSO, A. I. I.; VILLAS BOAS, R. L.; HIGUTI, A. R. O. Germinação de sementes de alface obtidas de plantas cultivadas com diferentes doses de fósforo. Semina: Ciências Agrárias, Londrina, v. 32, n. 2, p. 591-598, 2011.

KIEHL, E. J. Fertilizantes orgânicos. Pircacicaba: Agronômica Ceres, 1985. 492 p.

MAGUIRE, J. D. Speeds of germination-aid selection and evaluation for seedling emergence and vigor. Crop Science, Madison, v. 2, n. 1, p. 176-177, 1962.

MARCOS FILHO, J. Fisiologia de sementes de plantas cultivadas. Piracicaba: Fealq, 2005. 495 p.

NAKAGAWA, J.; CAVARIANI, C.; GUISCEM, J. M. Efeito da adubação fosfatada e potássica no teste de condutividade elétrica de sementes de aveia-preta. Revista Brasileira de Sementes, Brasília, v. 23, n. 2, p. 302-308, 2001.

NAKAGAWA, J.; ROSOLEM, C. A.; MACHADO, J. R. Efeitos da adubação fosfatada no vigor das sementes de amendoim. Revista Brasileira de Sementes, Brasília, v. 2, n. 1, p. $67-74,1980$.

PÁDUA, G. P.; VIEIRA, R. D. Deterioração de sementes de algodão durante o armazenamento. Revista Brasileira de Sementes, Brasília, v. 23, n. 2, p. 255-262, 2001. 
RAIJ, B. van; CANTARELLA, H.; QUAGGIO, J. A.; FURLANI, A. M. C. Recomendações de adubação e calagem para o Estado de São Paulo. 2. ed. Campinas: Instituto Agronômico \& Fundação IAC, 1996. 285 p.

ROSSETO, C. A. V.; NAKAGAWA, J.; ROSOLEM, C. A. Efeito da adubação potássica e da época de colheita na qualidade fisiológica de sementes de canola (Brassica napus L. var. oleifera Metzg.). Revista Brasileira de Sementes, Brasília, v. 19, n. 2, p. 349-354, 1997.
VIEIRA, R. D.; CARVALHO, N. M. Teste de vigor em sementes. Jaboticabal: FCAV/FUNEP, 1994. 164 p.

ZUCARELI, C. Adubação fosfatada, produção e desempenho em campo de sementes de feijoeiro $\mathrm{cv}$. Carioca Precoce e IAC Carioca Tybatã. 2005. Tese (Doutorado em Agronomia) - Universidade Estadual Paulista, Botucatu. 
